\section{HONOURS, AWARDS, APPOINTMENTS}

Dental Postgraduate Dean

Dr Jane Luker has been appointed Dental Postgraduate Dean of NHS South West LETB and will succeed Alasdair Miller in November 2013. Dr Luker is Deputy Medical Director of the University Hospitals Bristol and Consultant in Dental \&t Maxillofacial Radiology at Bristol Dental Hospital. She is also currently President of the British Society of Dental \& Maxillofacial Radiology.

\section{Double research award}

Svetislav Zaric, Associate Professor in Biomedical Science at Plymouth University Peninsula Schools of Medicine and Dentistry, has been awarded the International Association for Dental Research Lion Dental Research Award for microbiology/immunology, intended to support improvements in oral health services by junior researchers. Professor Zaric's second accolade is the Oral and Dental Research Trust Award sponsored by GSK - the only dental research charity - which has awarded only five grants this year.

\section{HPV LINKED TO A THIRD OF THROAT CANCER CASES}

A recent study published in the Journal of Clinical Oncology ${ }^{1}$ suggests one in three people diagnosed with oropharyngeal cancer are infected with a form of the human papillomavirus (HPV).

Prediagnostic blood samples, collected up to ten years before diagnosis, were analysed for HPV antibodies in a cohort of 638 head and neck cancer patients. HPV16 E6 - one of HPV's key cancer-causing proteins - was present in the blood samples for $34.8 \%$ of patients with throat cancer, compared to less than 1\% percent of those who were cancer free. Whilst most people will be infected with HPV at some point in their lives, it is two particular strains, HPV16 and HPV18, that are most likely to cause cancer.

However, five-year survival rates for patients who were HPV16 E6 seropositive were higher at 84\% than those without the antibodies (58\%) whose throat cancer had different aetiological causes such as alcohol or tobacco use.

These results could have important implications for early diagnosis and risk assessment, as well as the clinical impact of the HPV vaccine, broadening its protective sphere against not only cervical cancer, but oropharyngeal cancers and others, though further research is needed.

1. Kreimer A R, Johansson $M$, Waterboer T et al. Evaluation of human papillomavirus antibodies and risk of subsequent head and neck cancer. J Clin Oncol 2013; 31: 2708-2715.

By Laura Pacey

\section{PHOTO STORY}

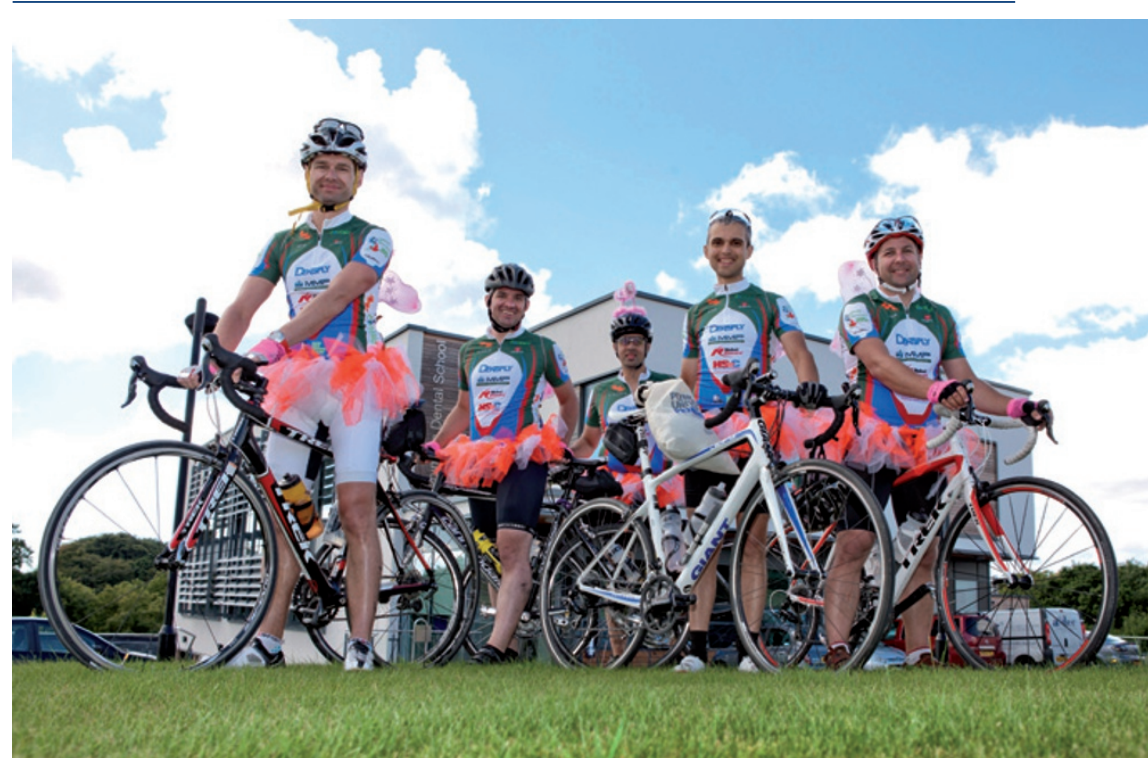

Five ‘tooth fairies' - Army dentists in heavy disguise - visited Plymouth University Peninsula Schools of Medicine and Dentistry in the early stages of a trip from Land's End to John 0'Groats. The team were aiming to break the world record for the fastest time on this journey dressed in fancy dress, as well as raising money for the Army Benevolent Fund and Dentaid.

\title{
EASTERN AGM
}

The Eastern Counties Branch Annual General meeting and installation of the new president will take place on Wednesday 6 November 2013 at Ravenwood Hall, Rougham, IP30 9JA at 8 pm and will be followed by an informal meal. The meeting will be preceded by a Branch Council meeting at 6.30 p.m. Members wishing to attend should contact Malcolm Heath, Branch Secretary. 